\title{
Teaching Renewable Energy System Design and Analysis with HOMER
}

\section{Dr. Radian G Belu, Drexel University (Tech.)}

Dr. Radian Belu is Assistant Professor within the Engineering Technology (ET) program - Drexel University, Philadelphia, USA. He is holding a PHD in power engineering and the other in physics. Before joining to the Drexel University Dr. Belu hold faculty and research positions at universities and research institutes in Romania, Canada and United States. He also worked for several years in industry as project manager, senior engineer and consultant. He has taught and developed undergraduate and graduate courses in power electronics, power systems, renewable energy technologies, smart grids, control theory, electric machines, instrumentation, radar and remote sensing, numerical methods and data analysis, space and atmosphere physics, and applied physics. His research interests included power system stability, control and protection, renewable energy system analysis, assessment and design, smart microgrids, power electronics and electric machines for wind energy conversion, radar and remote sensing, wave and turbulence simulation, measurement and modeling, numerical modeling, electromagnetic compatibility and engineering education. During his career Dr. Belu published eight book chapters, several papers in referred journals and in conference proceedings in his areas of the research interests. He has also been PI or Co-PI for various research projects United States and abroad in power systems analysis and protection, load and energy demand forecasting and analysis, renewable energy, microgrids, turbulence and wave propagation, radar and remote sensing, instrumentation, atmosphere physics, electromagnetic compatibility, and engineering education.

\section{Dr. Richard Chiou, Drexel University (Eng.) \\ Ms. KETKI GHAISAS, Drexel University \\ Prof. Tzu-Liang Bill Tseng, University of Texas, El Paso}

Dr. Tseng is an associate professor of Department of Industrial, Manufacturing and Systems Engineering at the University of Texas at El Paso (UTEP). He received his M.S. degree in Industrial Engineering (concentration on manufacturing systems and decision sciences) from the University of Wisconsin at Madison in 1993 and 1995 respectively and Ph.D. in Industrial Engineering from the University of Iowa in 1999. Dr. Tseng is also a Certified Manufacturing Engineer from Society of Manufacturing Engineers since 2002. Dr. Tseng is specialized data mining, knowledge management, decision sciences and statistical analysis, specifically in the area of IBDSS. Over the years, he has served as principle investigators sponsored by NSF, NIST, NASA, DoEd, , KSEF and industry like LMC, GM and Tyco Inc.

Dr. Tseng delivered research results to many refereed journals such as IEEE Transactions, IIE Transaction, IIE Proceedings, International Journal of Production Research, Journal of Manufacturing Systems, Expert Systems with Applications and Computer Standards \& Interfaces and other conferences (over 160 refereed publications. Moreover, he was listed in the "Who's Who in America" for his achievement in 2005 and he also received 2009 and 2013 University Research Awards at University of Texas at El Paso. He is currently serving as an editor of Journal of Computer Standards \& Interfaces (CSI) and editor boards of International Journal of Data Mining, Modeling and Management (JDMMM) and American Journal of Industrial and Business Management (AJIBM). He is currently a Senior Member of IIE and SME and is actively involved in several consortia activities. 


\title{
Teaching Renewable Energy System Design and Analysis with HOMER
}

\begin{abstract}
Equipping engineering students with the skills and knowledge required to be successful global engineers in the 21st century is one of the primary objectives of undergraduate educators. Enabling students to practice self-directed learning, to find solutions to design problems that are sustainable to the application requirements, to have appropriate skills and knowledge, as well as the familiarity of the modern software packages, tools and equipment used in today industries are major goals of all engineering or engineering technology programs. This paper presents how the uses of HOMER (Hybrid Optimization Model for Electric Renewable) software package can be a valuable tool for renewable energy education (design, modeling and analysis of renewable energy systems). However, today there are quite a few programs for the renewable energy design, analysis and modeling. Some of them are more complexes, others user-friendlies, while others too simple. Here, this software package has been considered to have all the features and tools necessarily to make a good option, while being not too complicated and complex for undergraduate engineering or engineering technology students with limited or not previous knowledge in the areas of renewable energy systems. HOMER optimization software package can be used for design, model and analysis to determine the optimal architecture, structure, size and control strategy of the hybrid power system. It can perform comparative economic and modeling analysis on a distributed generation power system in order to get the best solution in terms of cost, performances, size and structure. Several educational modules were developed, are in process or planned to be developed. The first developed module is about how to use, interact and understand with HOMER software package. Other modules are focusing on how design, analyze and optimize hybrid power systems (implying various combinations of wind, solar, fuel cells and batteries). A module underway to be developed is one that can be considered as a guide on how to use renewable energy to secure a sustainable grid. The paper is also discussing the technical skills gained by students using the software HOMER package. Finally by using HOMER students have exposure to non-technical engineering skills, such as economic feasibility, logistic and decision on hybrid power systems. We are hoping the materials presented herein can be used as the starting point for other instructors considering the use of HOMER package as teaching help, design and analysis tool in renewable energy courses.
\end{abstract}

\section{Introduction}

Due to the adverse effects of pollution from fossil fuel-based power plants, alternative electricity generation is being today widely and speedily accepted. In the same time, the electricity demand is increasing and the conventional energy resources are fast depleting, making the exploitation of renewable energy sources for the electricity generation the only alternative. Carbon tax, pollution reduction and emissions trading legislation, or the increasing oil price paving the way for environmental accountability and sustainability. The renewable energy application has become an important alternative as power provider in rural electrification and for standalone power applications. Renewable energy sources have the major advantage in that they can reduce carbon emissions without the use of underground resources, but have disadvantage also in that their energy output vary under different weather and geographical conditions. In order to compensate for these short-comings, micro-grid configurations of various renewable energy sources 
equipped with energy backup systems are considered viable options for supplying energy more reliably. Applications of renewable energy at a chosen location are through solar radiation via photovoltaic (PV) panels, wind turbines and battery. Systems based on a single renewable energy source tend to be oversized to accommodate load demand, while combinations of two or more sources, the hybrid power systems improve load factors, reduce investment, maintenance and replacement costs as the renewable sources can complement each other. However the evaluation of the correct type of renewable energy system needs to be done so that the system needs to be optimized, usually through designed software packages for modeling, analysis and optimization.

In the last two decades there have been significant advances in renewable energy technologies, as well as increased demands for engineers and technicians trained in these areas, requiring innovative curricula, new courses and laboratories to educate students to work in this rapidly developing industry and to help professionals become acquainted with these new technologies. However, the pace of change in education curriculum is growing exponentially due to legislative changes, financial or administrative constraints. Engineering education moves into the twenty first century charged with an environmental agenda due to response to wider changes in the society. Educators are regularly modifying curriculum content to embrace technological changes in the learning outcomes. In modern world where everything changes at an extremely fast pace keeping up to date with technology is not only desirable but necessary. The renewable energy is highly interdisciplinary and crosses over between a numbers of research areas, making it quite difficult to be covered in a single course. Renewable energy technologies have strong potential for hands-on multi-disciplinary project-based learning. In particular, projects within sustainable engineering and renewable energy technologies can readily involve electrical, mechanical, computer, civil, and chemical engineering aspects while still being accessible to undergraduate students. A natural and efficient way of teaching and embedding renewable energy technologies into curriculum is the problem-oriented and project-based learning approach ${ }^{1-15}$

Engineering and engineering technology programs must offer a relevant and validated curriculum that prepares students for post-graduation success ${ }^{3,4}$. Courses that cover traditional subject matter in mathematics, sciences, materials, engineering sciences, economics and related topics provide the foundation of knowledge upon which specific skill sets are added depending on emphasis. However, it is critical for engineering/technology to transition from theoretical work in the classroom and experiential learning with applications of technology and design. The main objective of senior design courses in engineering and engineering technology curricula is to bridge the gap between theory and real world practice. Accordingly, the proposed senior projects should include elements of both credible analysis and experimental proofing such as design and implementation as discussed in ABET criteria ${ }^{1}$. Additionally, the senior design courses can serve as an excellent culminating experience in the program of study when it focuses on research and design projects that have practical value to consumers or to industrial customers. Due to this unprecedented growth in the renewable energy use for electricity generation, combined with the interest of keeping students abreast of the current scientific and technological developments, it was important and timely to develop an upper-level course on renewable energy. There also is a well-documented demand and need in offering courses and training in renewable energy areas ${ }^{6-}$ ${ }^{10}$. This course focuses on wind energy conversion, solar/PV and fuel cell systems, and the impacts of the intermittency of renewable energy on power systems ${ }^{10}$. We also strongly believe 
that renewable energy and sustainability topics must be included when it is appropriate into other engineering courses in our program, an essential aspect of the engineering education.

\subsection{Renewable Energy Technology Course Contents}

Our upper-level undergraduate course on renewable energy systems was first offered in the Spring 2010 quarter, and since is offered every year as core course. It is a three credit-hour course, using several textbooks, due to interdisciplinary nature of the subject. It primarily focuses on wind energy, wind power systems and solar/photovoltaic energy generation ${ }^{10-18}$. To a lesser extend it focuses on other renewable energy sources and related technologies. Wind and solar energy and wind and solar power systems make up about $80 \%$ of the course since wind and solar energy represent the fastest growing areas of renewable energy in the past decade. Therefore the key areas that the course focuses are the wind and solar energy sources and the related technologies. The teaching modules of this course consist of the following topics each of them presenting a special type of renewable energy and dispersed generations. The renewable energy course and power system is divided into ten modules. Each module can be completed within three to five 50-minute lecture sessions. The outline of the course includes (ten 3-hour lectures):

1. Basic principles of energy generation

2. Introduction to renewable energy systems

3. Electric machines Basics; Electric machines for renewable

4. Solar energy fundamentals

5. Photovoltaic energy production; Photovoltaic systems

6. Wind energy resource characteristics

7. Wind energy conversion systems: aerodynamic and electric aspects

8. Wind energy modeling aspects

9. Fuel cell systems

10. Distributed generation and power quality

Since this course deals mainly with the analysis and the components of the wind and solar energy conversion systems, and the integration and interconnection to the power grid, the desired prerequisites include energy conversion, electric machines and co-requisites a course in power electronics. Students are expected to be well around in general renewable energy issues, electric machines and energy conversion technologies. They are expected to be particularly skilful in analyzing and solving wind and solar energy systems and related problems.

\section{Using HOMER in Teaching Renewables and Sustainable Design}

Engineering students, instructors and professional should be aware that there are several software packages that can be used to simulate renewable energy and hybrid power systems to provide cost effective, optimum size and design solutions for specific load, fuel usage and environmental constraints and requirements. By interacting and learning to use these software packages students are exposed to new technical and non-technical skills as ones facing the professional engaged in modern industries. With these knowledge and skills the students are able to get feasible solutions of renewable energy systems and to become familiar with the current renewable energy industry practice $^{11,16-27}$. The HOMER software package used here, can simulate, analyze and model 
renewable energy or hybrid power systems that can include generation, cogeneration, solar/PV systems, batteries, wind turbines, micro-turbines, hydropower, and fuel cells among other inputs.

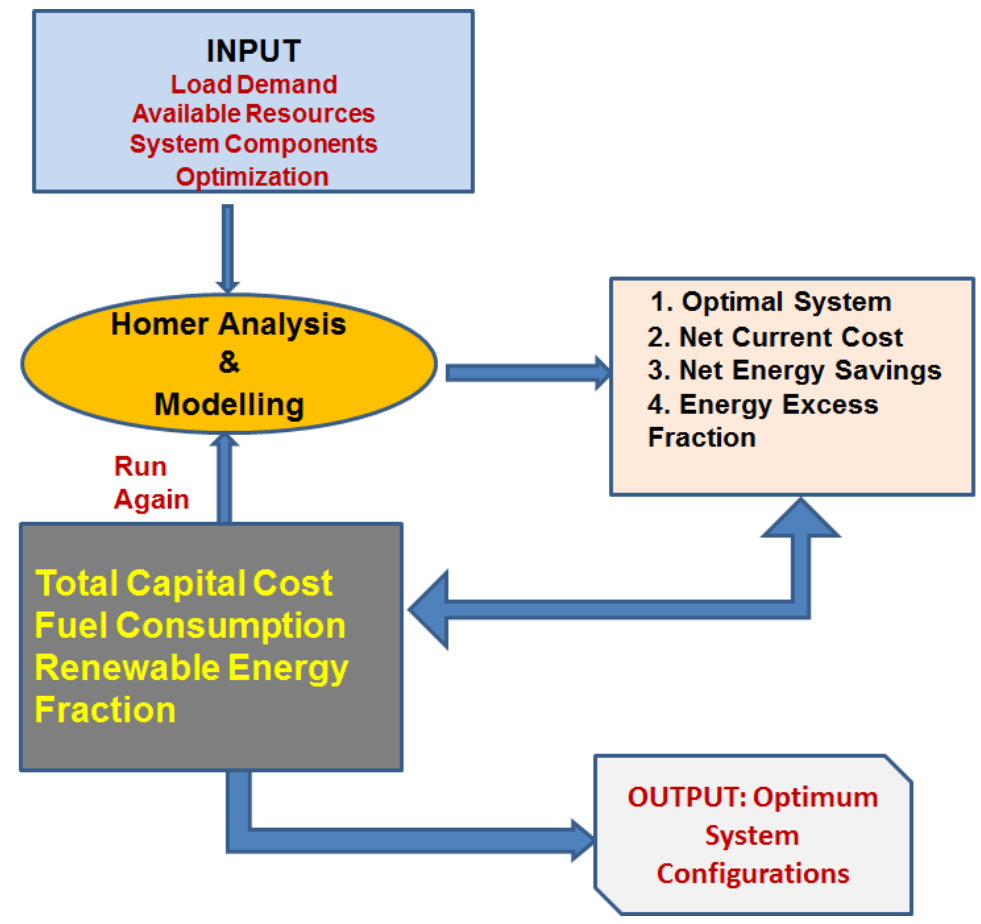

Figure 1 HOMER software package architecture

Simulation programs and software packages are the common tools for optimizing and evaluating the performances of the hybrid power or renewable energy systems, HOMER being one of the most used. By using such tools, the optimum configuration can be found by comparing the performance and energy production cost of different configurations. HOMER was originally developed at the National Renewable Energy Laboratory (NREL), United States. A commercial version has been developed, upgraded and distributed by HOMER Energy, LCC and is used by the authors as teaching aid for our renewable energy course. It can be used to design, analyze and model micro-power and hybrid power system's configurations with various energy resources for economics and sizing to determine the optimal combination of them to meet the load demand and the user requirements. Figure 1 shows the basic architecture of this software package. It shows the calculation result of the number of cases of different renewable energy sources under weather conditions, load demands, capacity ranges, fuel costs, and carbon emission constraints to select the optimum system. HOMER software package can facilitate the design and analysis of hybrid power systems for both stand-alone and grid-connected applications. Input information to be provided to HOMER includes: electrical loads (one year of load data), renewable resources, component technical details and costs, constraints, controls, type of dispatch strategy, etc. It designs an optimal power system to serve the desired loads, performing several simulations to ensure best possible matching between supply and demand in order to design the optimum system. It uses life cycle cost to rank order these systems, while can simulate the operation of a system by making energy balance calculations for each of the 8,760 hours in a year. For each hour, HOMER compares the electric demand in the hour to the energy that the system can supply in that hour, and calculates the flows of energy to and from each component of the system. 
HOMER performs the energy balance calculations, system cost calculations for each of the considered system configuration, listing all of the possible system sizes, sorted by Net Present Cost (NPC). HOMER includes several energy component models, and evaluates suitable options considering cost and availability of energy resources. Grid connection is also considered in HOMER design procedure. It requires initial information including energy resources, economical and technical constraints, energy storage requirements and system control strategies. Inputs like component type, capital, replacement, operation and maintenance costs, efficiency, operational life, etc. are also required. HOMER has widely been used in previous renewable energy system case studies taking place in the literature. Both grid-connected and stand-alone systems have been investigated, consisting of various combinations of renewable energy sources and conventional systems such as diesel generators have also been considered in many studies. Many demonstration-level and experimental micro-power systems of renewable energy sources have much focused on the installation of renewable energy sources without enough and thorough investigation of the feasibility and the optimal combination of the resources and thus have met numerous problems including failure to meet the load demand, economically unacceptable system configuration ${ }^{25-27}$

\section{HOMER Hybrid Power System Analysis}

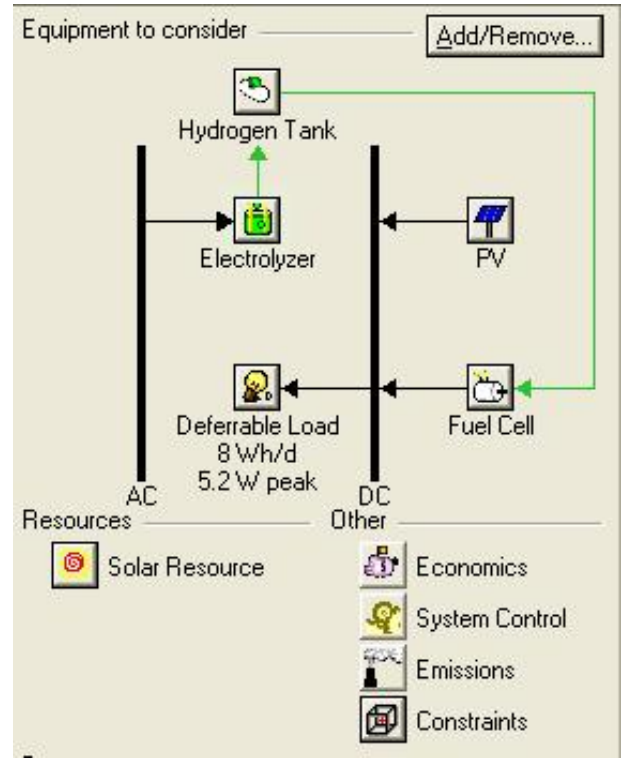

Figure 2 Configuration in HOMER of a PV-fuel cell hybrid power system

To realize the potential of distribution generation, generation and load must be taken as a subsystem. This system may use any combination of generation, load and storage technologies and can operate in grid connected mode or autonomous mode. Some examples of micro power system or microgrid are solar-battery serving a remote load, wind-diesel system serving an isolated village, a grid connected natural gas microturbine providing heat to a factory. Micropower system consists of electric and thermal loads and any combination of PV modules, wind turbine, small hydro, biomass power generation, microturbines, fuel cells, reciprocating engine generators, batteries and hydrogen storage. The analysis and design of micro-power system is challenging due to large number of design options and uncertainty in key parameters such as load size and future fuel price. Renewable energy sources add further complexity because the 
output may be intermittent, seasonal and non-dispatchable and the availability is uncertain. Once HOMER is open the user may start by adding/removing buttons on the upper left, enabling the equipment and components to be used in simulation and analysis, as one shown in Fig. 2

\subsection{System Descriptions}

The proposed hybrid power systems, used as teaching aids are designed based upon the certain important sensitivity variables to optimize the cost \& size effectively. Hence, before designing the model, certain parameters like solar irradiation, wind speed and load profile must be evaluated. It's presented in the following subsections of this paper. Hybrid energy systems with renewable generation are built in many remote areas or for special applications where the renewable resources are abundant and the environment is clean. To determine the system size, we formulate an optimization problem that minimizes the total construction and operation cost subject to maximum tolerable risk. Simulations and analyses, by using the package are used to determine the feasible set of the optimization problem. These simulation and analyses are designed and implemented to enhance the students' renewable energy knowledge and applications. PV panels, wind turbines, fuel cells, power converters, batteries, generators, electrolysers are among of many of the system components to be considered. The type and size of the load used and its characteristics is one of the most important inputs since it determine the system energy demand and is critical for system optimization, architecture, size and cost.

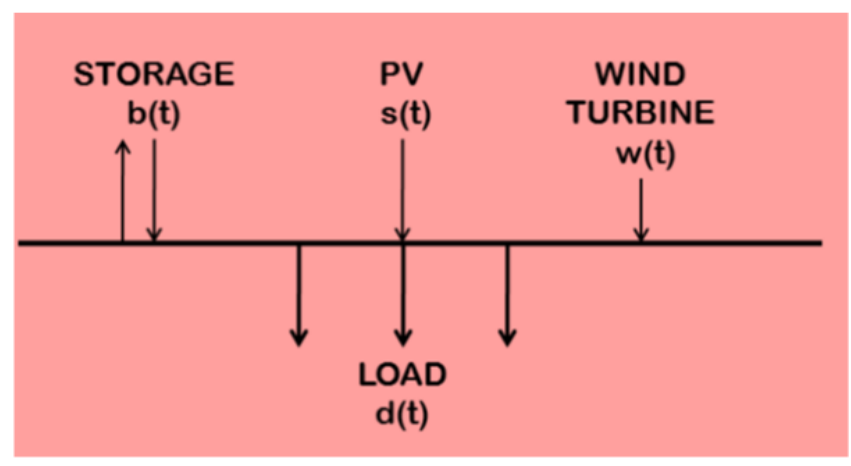

Fig. 3 The hybrid energy system with PV/ wind turbine/ battery storage

During our 10-week renewable course students are required to form a team of 3 to 4 by their preferences. Each team is in charge with a hybrid power system project. The team may propose the project or select from a list provided by the instructor. These projects are a good example of multi-disciplinary cooperation of different engineering disciplines as well as providing valuable hands-on experience to the students. In addition to providing useful lessons in teamwork and project management, the project will provide a working demonstration wind and solar energy system $^{9-12}$. During the final month of the fall quarter section of the course, each student team (formed by three to four individuals) is given partial specifications for a renewable energy conversion application. The team builds it initially with the function module and/or using circuit simulation packages. Each team demonstrates the finished project to the entire class. Each term a written report summarizing the project is also required as part of the senior project design course. This process synthesizes all of the basic materials in the core courses and can also be used as part 
of the requirements of the senior project requirements for each student. In the following subsections of the paper we are presenting some the HOMER applications.

\subsection{Solar Radiation and Wind Speed Data}

The HOMER simulator will be driven by traces of solar power output $\mathrm{s}(\mathrm{t})$ and wind power output $\mathrm{w}(\mathrm{t})$ (see Figure 3 for details). These traces are obtained from empirical data on solar radiation and wind speed at the interest sites or at locations close to that sites. For solar resources the time zone where the system will is also important factor. HOMER has it own wind and solar database that gives hourly, daily, monthly and annual averages. However, the wind resources are little bit more complicated than the solar resources because their inconsistence and variations. The wind speed and direction data from at least one year of measurements is needed in order to have a good wind resource assessment and estimate. Figure 3 is showing the power flow in a system consisting of wind turbine, PV panel, storage unit and a load, while Figure 4 is giving the solar radiation for a selected location.

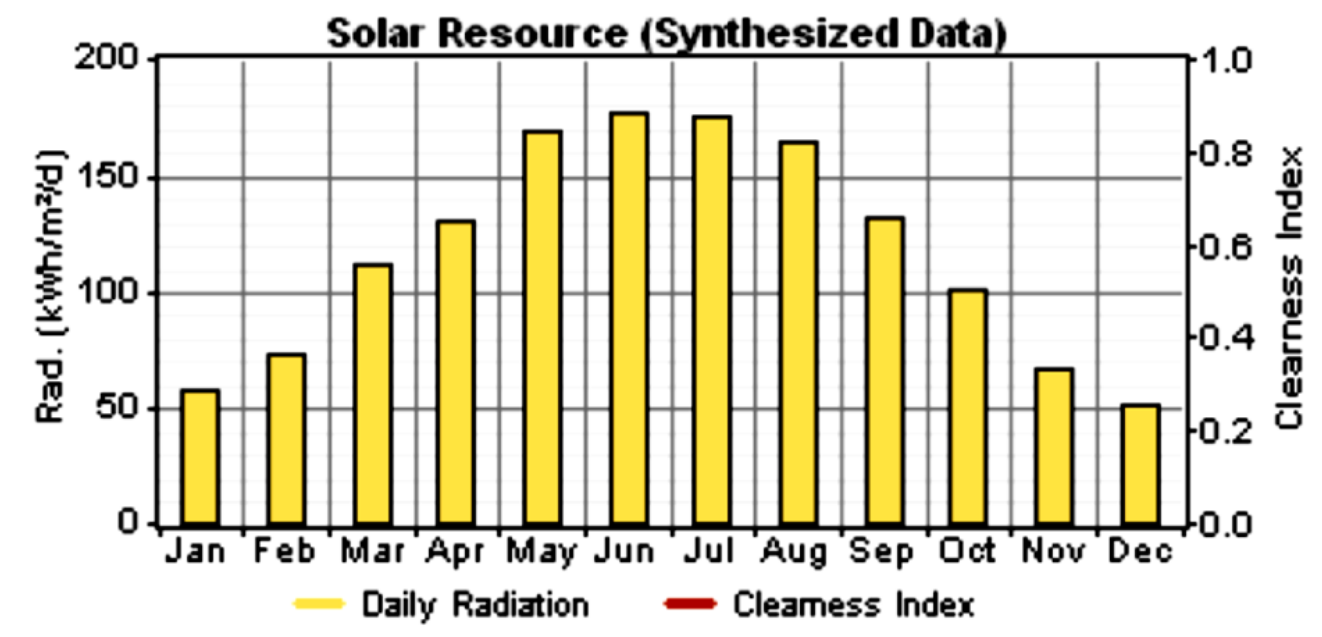

Figure 4 Typical yearly profile of the solar radiation

HOMER synthesizes solar radiation values for each of the 8760 hours of the year. Its algorithms produces realistic hourly data, being easy to use, requiring only the latitude and the monthly averages, while displaying realistic day to day and hour to hour patterns. The synthetic data are created with certain statistical properties that reflect global average value. However, generated data for a particular location will not exactly replicate the characteristics of the real solar radiation. But tests show that synthetic solar data produce virtually the same simulation results as real data. HOMER synthetic wind data generator is little different to use than the solar data as it requires four parameters, in order to generate wind statistics for this specific site. A user starts by specifying system parameters and hourly electrical load, wind and solar resource data. For each simulated hour the software calculates global irradiation at the photovoltaic array titled surface, calculates the output energy from the array, and performs energy balance at the DC and AC buses to determine amount of energy taken from or transferred to the electrical grid. Energy balance at the DC bus takes in consideration the storage component when present. The software keeps record of hourly, daily monthly and one year simulation results. It displays these results in 
a tabular format. Results also include economic analysis that takes into account investment costs and financial benefits projected over the life time of the project.

\subsection{Load Profile}

An important consideration of any power generating system is load requirements and characteristics, not only for load itself but also for the efficiency and reliability of power transmission. The load factor for the project is important in the design process. The project team is usually distributed strategically over the $24 \mathrm{~h}$ period to improve the system load factor to minimize the possibility of errors and to optimize the system size and structure. Figure 5 shows monthly average load profile. The peak load requirement decides the size, structure and architecture of the proposed system. The model of each project has been developed using HOMER, consists of a PV, WG(s), a battery, and fuel cell. The schematic of this hybrid power system is shown in Fig. 5. In order to verify the system performance under different situation, simulation studies have been carried out using real weather data (solar irradiance and wind speed). The goal of the optimization process is to determine the optimal value of each decision variable that interests the modeler. A decision variable is a variable over which the system designer has control and for which HOMER can consider multiple possible values in its optimization process. Decision variables in HOMER include: 1) the size of the PV array; 2) the number of WG; 3) the battery capacity; and 4) the size of the DC-AC and DC-DC converters. While Fig. 5 is showing a snap shot of the HOMER solar input data.

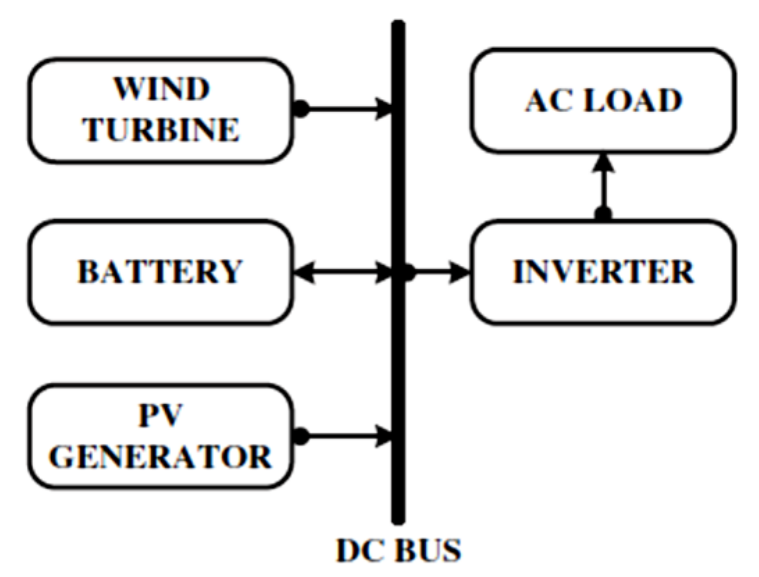

Figure 5 Project block diagram

\subsection{System Optimization}

The optimization process is done after simulating the entire possible solutions of hybrid renewable energy system configuration. HOMER display a list of configurations sorted based on the Total Net Present Cost (TNPC). It can be used to compare different types of system configuration from the lowest to the highest TNPC. However, the system configuration based TNPC is varied depending to the sensitivity variables that have been chosen by the designer. HOMER can repeat the optimization process for every selection of sensitivity variables for the hybrid renewable energy system. The sensitivity variables are such as the global solar, wind speed and the price of fuel that maybe used in the proposed system. Then, the list of various configurations of hybrid renewable energy will be tabulated from the lowest to the highest 
TNPC. The optimal solution of hybrid renewable energy system is referring to the lowest TNPC. In a hybrid power system, a component generates, delivers, converts and stores energy. In this HOMER analysis, solar PV, wind turbines, and run-off river hydropower are the intermittent resources and the bio-diesel is kept for backup. Batteries and converters are for storing, converting electricity respectively. The performance and cost of each of components is a major factor for the overall cost and the design. HOMER performs the simulation for a number of prospective design configurations. After examining every design, it selects the one that meets the load with the system constraints at the least life cycle cost. It also performs its optimization and sensitivity analysis across all components and their resources, technical and cost parameters, and system constraints and sensitivity data over a range of exogenous variables. The competitiveness of the best suited hybrid power system for a specific application is then used in the design selection process. Sensitivity analysis eliminates all infeasible combinations and ranks the feasible combinations taking into account uncertainty of parameters. HOMER allows taking into account future developments, such as increasing or decreasing load demand as well as changes regarding the resources, for example wind speed or solar radiation variations, or fuel prices.

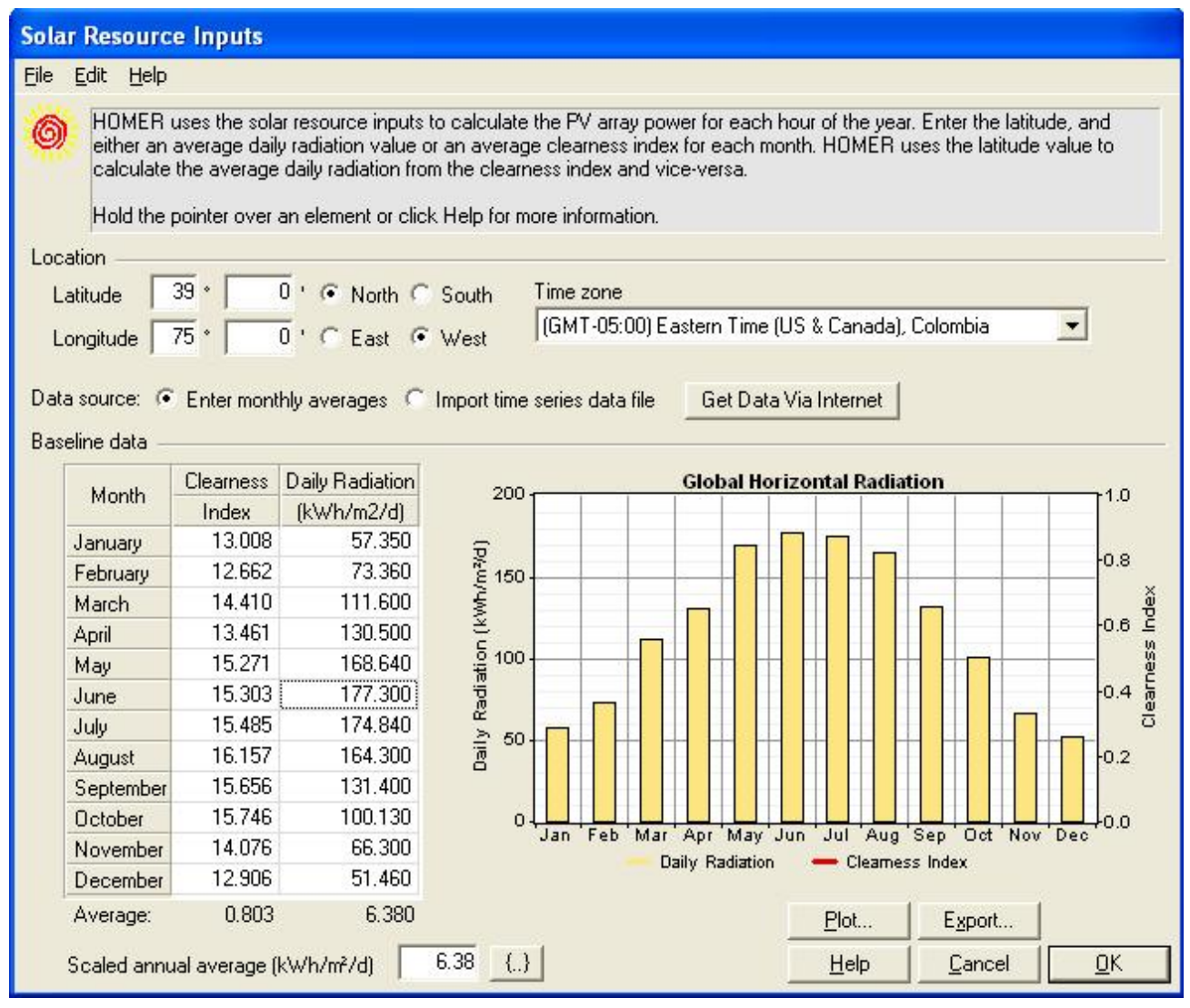

Figure 6. PV/Solar input

\section{Student Learning Experience}

The inclusion of HOMER in a renewable energy course could provide additional added values to the course. In the authors view, it is an excellent tool not only for designing and analyzing renewable energy systems, but also for improving learning such systems because of its friendly 
methodology, capabilities and the available open resources and programs. Any undergraduate engineering and technology student could use it without any or little previous knowledge in these areas, requiring very little training for a user to employ it to design quite complex hybrid power and renewable energy systems. So it can bring technical skills related to energy systems to undergraduate engineering and technology students or professionals interested to learn and expend their knowledge in these areas. Moreover HONER can be a useful tool and aid for students' research projects or to engage the students in renewable energy related research and project. In next section we are presenting some examples of how HOMER could be integrated as part of the existing or planed renewable energy courses. After interacting and learning the HUMER use students and other users (teaching and research assistants, laboratory engineers or technicians) are expected to get technical and non-technical skills required in renewable energy or hybrid power system analysis, modeling and design. Some of these skills include: ability to apply economic analysis and to provide the optimum solutions to lower the cost; ability to design hybrid power systems, components and processes to meet the needed requirements; ability to learn about local codes and standards; ability to identify, formulate and solve engineering problems; knowledge how energy systems work and operate; or ability to apply logistics and make better decisions energy systems.

The renewable energy course was first time offered in the 2009-2010 academic year, during 2012-2013 academic year it was approved by our university senate as upper level course. During Sumer 2013 quarter one of the authors taught it with the inclusion of HOMER software as teaching aid. At the end of the summer quarter, all students have been requested to answer (with a five point scale: 1-very poor, 2-poor, 3-satisactory, 4-good and 5-very good) an anonymous questionnaire, as shown in table 1 . According to the results, the new project-based approach received a 3.9/5.0 rating, comparing with an average rating of 3.4/5.0 for the all courses at our program. The results from the students' feedback have been extremely positive with the regard to the HOMER based renewable energy-related projects. The majority of students felt that such projects enhanced their understanding of the theoretical materials and made the course more interesting. Similar surveys were or are planned to be conducted at the end of each quarter of the future academic years, when the course will be offered.

\begin{tabular}{|l|l|}
\hline Q1 & Have you learn more than expected with the course? \\
\hline Q2 & Is the team project useful to you? \\
\hline Q3 & It was useful the use of HOMER during the laboratory and end-of-term project? \\
\hline Q4 & $\begin{array}{l}\text { What was the level of "hands-on” experience has been achieved by learning } \\
\text { HOMER? }\end{array}$ \\
\hline Q5 & Please, provide an overall evaluation of the course. \\
\hline
\end{tabular}

Table 1: Questionnaire for the evaluation of the renewable energy course, using HOMER as teaching aid

\section{Conclusions and Future Work}

The design experience develops the students' lifelong learning skills, self-evaluations, selfdiscovery, and peer instruction in the design's creation, critique, and justification. Students learn 
to understand the manufacturer data sheets, application notes, and technical manuals and component specifications. The experience of teamwork, prototype design and test, which would be difficult to complete individually, gives the students a sense of satisfaction and accomplishment that is often lacking in many engineering courses, not including projects. Furthermore, the design experience motivates student learning and develops skills required in industry. The students were able to make satisfactory estimations and calculations of these projects. Their results reflect that they have understood well all the basic ingredients of the modeling techniques and design of the renewable energy systems. They were also very pleased with the approach used to teach them.

HOMER software package is a useful tool that can really help the undergraduate engineering and technology students in the area of design and analysis of renewable energy or hybrid power systems. HOMER is a very easy to use and learn software package, requiring only basic knowledge in the areas of energy and power systems. The software package demonstrate that with just a little training any undergraduate engineering and technology student are able to design and analyze renewable energy systems. It prepare the students with a useful tool used in industry and maybe to make some students to pursue a career in energy industry or to enroll in graduate programs in the energy field. It is important to encourage students to learn to use such kind of software packages that work with renewable energy systems. Because by taking the advantage of such tools students can learn and adapt better solutions to fix the energy problem issues. It is is important to keep in mind that how we are using the energy today will shape the way how we live in the future.

\section{References}

1. Engineering Accreditation Commission, "Criteria for Accrediting Engineering Programs," http://www.abet.org/criteria.html. (2002).

2. Petty, I.: Vision 2020 - Education in the next Millennium. In: Hagström, A. (Ed.), Engineering Education: Rediscovering the Centre (Proc. SEFI Annual Conf., Winterthur and Zürich, 1999) pp. 27-35.

3. S. Santoso and W.M. Grady, Developing an Upper-Level Undergraduate Course on Renewable Energy and Power Systems, Proceedings, 2005 IEEE PES General Meeting, San Francisco, CA, June 12-16, 2005.

4. M. H. Nehrir, A course on alternative energy wind/PV/fuel cell power generation, IEEE Power Engineering Society Meeting, June 18-22, 2006, Montreal, Canada

5. R.G. Belu and A.C. Belu - Development a Web-based Course in Renewable Energy Sources, 2006 Annual ASEE Conference, Chicago, July 2006 CD Proceedings) \R.G. Belu and A.C. Belu - A Decision Support Software Application for Design of Hybrid Solar-Wind Power Systems- as Teaching-Aid, 2007 Annual ASEE Conference, and Exposition, Honolulu, Hawaii (CD Proceedings).

6. R.G. Belu and I. Husanu - An Undergraduate Course on Renewable Energy Conversion Systems for Engineering Technology Students, 2011 ASEEE Conference \& Exposition, June 26 - 29, Vancouver, BC, Canada (CD Proc.).

7. Gilbert M. Masters, Renewable and Efficient Electric Power Systems, Wiley Interscience, 2004

8. M.K. Patel, Wind and Solar Power Systems, CRC Press, 1999.

9. J.F. Manwell, J.G. McGowan, and A.L. Rogers, Wind Energy Explained, Wiley 2003.

10. R. Messenger and J. Ventre, Photovoltaic System Engineering, second edition, CRC Press, 2003.

11. T. Lambert and P. Lilienthal. HOMER: the micro-power optimization model: Produced by National Renewable Energy Lab. [Online]. Available: http://homerenergy.com/

12. R. G. Belu, A Project-based Power Electronics Course with an Increased Content of Renewable Energy Applications, June 14-17, 2009 Annual ASEE Conference and Exposition, Austin, Texas, 2009 (CD Proceedings). 13. R.G. Belu - Design and Development of Simulation System for Renewable Energy Laboratory, 2010 ASEEE Conference \& Exposition, June 20 - 23, Louisville, Kentucky (CD Proceedings).

14. R.G. Belu and D. Koracin - E-learning Platform for Renewable Energy Sources, 2010 ASEEE Conference \& Exposition, June 20 - 23, Louisville, Kentucky (CD Proceedings) 
15. R.G. Belu - Renewable Energy Based Capstone Senior Design Projects for an Undergraduate Engineering Technology Curriculum, 2011 ASEEE Conference \& Exposition, June 26 - 29, Vancouver, BC, Canada (CD Proceedings).

16. L. Arribas, L. Cano, M. Mata, and E. Llobet, "PV-wind hybrid system performance: A new approach and a case study," Renewable Energy, vol. 35, no. 1, pp. 128-137, 2010.

17. R.G. Belu - Power Electronics and Controls for Photovoltaic Systems, Handbook of Research on Solar Energy Systems and Technologies (Eds: Dr. Sohail Anwar, Dr. Salahuddin Qazi, and Dr. Harry Efstathiadis), IGI, Global, pp. 68-125, 2012 (DOI: 10.4018/978-1-4666-1996-8.ch004).

18. R.G. Belu - Using a Virtual Platform for Teaching Electrical Machines and Power Systems, 2013 ASEE Annual Conference and Exposition, Atlanta, USA, June 23-26, 2013 (CD Proceedings).

19. R.G. Belu R.G. and I. Husanu - First Results with a Virtual Platform for the Renewable Energy Technology Courses, 2013 ASEE Annual Conf. Exp, Atlanta, USA, June 23-26, (CD Proceedings).

20. R.G. Belu and I. Husanu - Embedding Renewable Energy and Sustainability into the Engineering Technology Curricula, 2012 ASEEE Conference \& Exposition, June 10 - 13, 2012, San Antonio, Texas (CD Proceedings). 21. R. Chiou, R.G. Belu, M. Mauk and E. Carr - Student Learning Experience from Renewable Energy Case Studies, 2013 ASEE Annual Conference and Exposition, Atlanta, USA, June 23-26, 2013 (CD Proceedings).

22. A. M. O. Haruni, A. Gargoom, M. E. Haque and M. Negnevitsky, "Dynamic Operation and Control of a Hybrid Wind- Diesel Stand Alone Power Systems”, IEEE Twenty-fifth Annual Applied Power Electronics Conference and Exposition (APEC), pp.162-169, 2010

23. Ahmad Rohani, Kazem Mazlumi, Hossein Kord, Modeling of ahybrid power system for economic analysis and environmental impact nin HOMER, Electrical Engineering (ICEE), 2010 18th Iranian Conference on, pp.819-823, 11-13 May 2010.

24. M.S. Hossan, M.M. Hossain, AR.N.M.R. Haque, "Optimization and modeling of a hybrid energy system for off-grid electrification," Environment and Electrical Engineering (EEEIC), $201110^{\text {th }}$ International Conference on , pp.I-4, 8-11 May 2011.

25. S. Jalilzadeh,A. Rohani, H. Kord, M. Nemati, Optimum design of a hybrid Photovoltaic/Fuel Cell energy system for stand-alone applications, in 6th Int. Conference on Electrical Engineering/Electronics, Computer, Telecommunications and Information Technology, ECTl-CON 2009, vol. OI, pp.152-155, 6-9 May 2009.

26. A. Souissi, O. Hasnaoui, A. Sallami, "Optimal Sizing of a Hybrid System of Renewable Energy for a Reliable Load Supply without Interruption”, European Journal of Scientific Research, Vol. 45, No. 4, 2010, pp. 620-629.

27. Lambert T, Gilman P, Lilienthal P. Micropower system modeling with HOMER. In: Farret FA, Simões MG, editors. Integration of alternative sources of energy. Hoboken (NJ): IEEE Press; Wiley-Inter-Science; 2006. p. 379418. 